\title{
ENTRE A DECADÊNCIA E A RENOVAÇÃO: estratégias de sobrevivência de antigos hotéis localizados no hipercentro de Belo Horizonte
}

\author{
Between degradation and renovation: survival strategies of \\ old hotels located in the bypercenter of Belo Horizonte
}

\author{
Janete Lara de Oliveira Bertucci ${ }^{[a]}$, Rafael Diogo Pereira ${ }^{[\mathrm{b}]}$ \\ [a] Doutora em Administração pela Universidade Federal de Minas Gerais (CEPEAD/FACE/UFMG), Belo Horizonte, MG - Brasil, \\ e-mail: janetelara@face.ufmg.br. \\ [b] Mestrando em Administração pela Universidade Federal de Minas Gerais (CEPEAD/FACE/UFMG), Belo Horizonte, MG - \\ Brasil, e-mail: rdp@cepead.face.ufmg.br
}

\section{Resumo}

Este estudo tem como objetivo identificar as estratégias utilizadas por antigos hotéis localizados no hipercentro de Belo Horizonte para sobreviver às transformações ambientais que afetaram o setor, tais como a degradação do hipercentro da cidade e o aumento da concorrência, bem como a outros fatores, tais como alterações na estrutura de propriedade e controle e, sobretudo, ao próprio tempo físico e histórico. Para compreensão do processo estratégico dessas organizações, foram utilizadas as contribuições teóricas de Mintzberg, Ahlstrand e Lampel (2000), que concebem a estratégia como um padrão consistente ao longo do tempo, bem como a tipologia estratégica de Miles e Snow (1978). Foi realizado um estudo qualitativo, por meio da técnica de estudos de caso, a partir de entrevistas em profundidade, realizadas com os sóciosproprietários e gestores dos três hotéis pesquisados, tendo todos esses mais de 40 anos de existência. As informações coletadas foram tratadas por meio da técnica de análise temática de conteúdo. Os resultados mostram que essas organizações adotam comportamentos estratégicos defensivos, apresentam uma capacidade relativa de escanear o ambiente que as cerca, minimizam a importância dos fatores exógenos, e suas estratégias geralmente emergem de um processo quase errático, mais com o objetivo de resolver um problema imediato do que propriamente de constituir um padrão estratégico. Embora as alternativas estratégicas utilizadas tenham permitido a sobrevivência dessas organizações, novos desafios e também perspectivas promissoras parecem exigir que essas organizações (re)definam seus processos estratégicos para o futuro.

Palavras-chave: Posicionamento estratégico. Gestão estratégia. Gestão de empresas familiares. 


\begin{abstract}
This study aims to identify the strategies used by old hotels in the hypercenter of Belo Horizonte to survive the environment transformations that have affected the sector, such as the degradation of this region in town and the increase of competition, as well as other factors, especially property and control structure alterations, and physi$\mathrm{cal} /$ historical time. For better understanding of this organizations' strategic processes, this work uses theoretical contributions by Mintzberg, Ahlstrand and Lampel (2000) that conceives strategy as a consistent pattern throughout time, as well as Miles and Snow's (1978) strategic typology. A qualitative study was conducted through case study technique using in depth interviews with owner-partners and managers of three researched hotels, all with more than 40 years of existence. The collected information was treated with content theme analysis. The results show that these organizations have adopted defensive management strategies, have an average capacity of scanning its surrounds, minimize the importance of exogenous factors, and their strategies emerge in an almost erratic process, mostly with the objective of solving immediate problems than properly constituting a strategic pattern. Even though these strategies so far have allowed these institutions to survive, new challenges and also promising perspective seem to demand from these companies to (re)define their strategic process in the future.
\end{abstract}

Keywords: Strategic positioning. Strategic management. Family-owned business management.

\section{INTRODUÇÃO}

Uma das principais contribuições da perspectiva processual da estratégia estaria em superar a dicotomia, largamente utilizada e defendida, de que a estratégia seria condicionada por um longo período de pensamento, a etapa de formulação, seguida por um longo período de ação, a fase de implementação (WILSON; JARZABKOWSKI, 2004). Na visão processual da estratégia, esses dois processos estariam incondicionalmente interligados, sustentando uma interconexão de mutualismo e interdependência. Em certas organizações ou em determinados contextos de alterações profundas e imprevisíveis, a estratégia geralmente não se desenvolve por meio de processos claros, ordenados e controlados, nem se encontra integralmente explícita em documentos formais (NICOLAU, 2001). Nesses momentos, ela usualmente está sendo estruturada por meio da aprendizagem acerca do ambiente e das capacidades internas da organização, sendo então buscadas as formas consideradas mais apropriadas para estabelecer as relações ambienteorganização. No processo de tentativa e erro, as ações desencadeadas, por sua vez, vão gerando resultados muitas vezes erráticos, cujas implicações para o futuro são desconhecidas, mas que tenderão a consolidar uma convergência de comportamento que configurará uma estratégia.

No hipercentro da cidade de Belo Horizonte, como provavelmente em um grande número de outras capitais brasileiras, existem ainda hoje hotéis fundados há muitos anos, inclusive alguns que remontam às décadas de 1920 a 1940. Alguns deles foram hotéis de luxo na época e hospedaram nomes famosos no cenário político, econômico, social e artístico. Hoje, já não apresentam mais o mesmo glamour, mas algumas de suas características instigam a curiosidade sobre como eles sobreviveram ao tempo e a grandes mudanças ambientais. Um razoável número desses hotéis resistiu ao processo de degradação do hipercentro da cidade acelerada no fim dos anos 1980, 1990 e nos primeiros anos deste século; suas taxas de ocupação são significativamente elevadas e, atualmente, com o processo de recuperação por que passa o hipercentro de Belo Horizonte, alguns deles vêm apresentando uma expressiva capacidade de revitalização. Partindo dessas observações empíricas, esta pesquisa buscou identificar as estratégias utilizadas por três hotéis localizados na região central de Belo Horizonte para sobreviver às transformações ambientais que afetaram o setor, tais como a degradação do hipercentro da cidade, o aumento na concorrência que ocorreu com a entrada em cena de grandes grupos hoteleiros, a mudanças de propriedade e controle e, sobretudo, ao próprio tempo físico e histórico. Hoje, diante de perspectivas mais otimistas em termos da revitalização do hipercentro da cidade, alguns desses estabelecimentos já exibem, mesmo que de forma incipiente, sinais de que novas estratégias estão sendo articuladas para tempos que se mostram mais promissores. 
Foi realizado um estudo qualitativo, por meio da técnica de estudos de caso, a partir de entrevistas em profundidade, realizadas com os sócios-proprietários de três hotéis localizados na região central de Belo Horizonte. As informações coletadas nas entrevistas foram tratadas por meio da técnica de análise temática de conteúdo (BARDIN, 1988), o que permitiu que os casos fossem redigidos, analisados e comparados.

\section{PROCESSO ESTRATÉGICO E TIPOLOGIA ESTRATÉGICA}

\section{Processo estratégico}

$\mathrm{Na}$ perspectiva de Mintzberg (1979), a estratégia é a força mediadora entre a organização e seu ambiente, e a formulação estratégica é a atividade que permite à organização interpretar o ambiente e desenvolver padrões consistentes de decisões para lidar com ele. Também a estratégia pode ser entendida como um padrão traduzido pela perpetuação consistente de um comportamento ao longo do tempo. Nesse sentido, as organizações desenvolveriam planos para o futuro e, ao mesmo tempo, extrairiam padrões de seu passado, o que configuraria a existência de estratégias pretendidas e realizadas. Contudo, nem todas as estratégias pretendidas costumam ser plenamente realizadas, o que explica o surgimento de outro tipo de estratégia: a estratégia emergente (MINTZBERG; AHLSTRAND; LAMPEL 2000). Nesse caso, padrões utilizados pouco a pouco vão ganhando consistência e convergindo para uma estratégia que não era conscientemente pretendida.

Estratégias realizadas, portanto, podem ser deliberadas, quando planejadas, ou emergentes, quando ocorrem de forma espontânea. No cotidiano organizacional, entretanto, é difícil caracterizar as estratégias como puramente deliberadas ou completamente emergentes. Se desconsiderada uma relação de complementaridade, a estratégia deliberada significaria a possibilidade de aprendizado zero para a organização, enquanto a estratégia emergente representaria a inexistência de controle por parte de seus gestores.

A importância de tal abordagem está em perceber a formação da estratégia como um processo em construção permanente, em que o planejamento meramente racional não é o único responsável pela criação das estratégias. Isso possibilita contemplar estratégias não intencionalmente traçadas provenientes da incerteza do contexto e que produzirão impactos diretos nos processos de adaptação organizacional. Assim, no presente estudo, o entendimento de estratégia, além de uma força mediadora entre a organização e o ambiente, também incorpora o que Mintzberg e Quinn (2001) designaram como estratégia artesanal, isto é, uma estratégia mais relacionada a um conhecimento tácito e íntimo da realidade organizacional, em que "[...] a formulação e a implementação fundem-se num processo fluídico de aprendizagem através do qual as estratégias criativas evoluem” (MINTZBERG; QUINN, 2001, p. 114).

\section{A tipologia estratégica de Miles e Snow}

A ainda relativa compreensão de como se dá o processo estratégico leva a outra questão: que tipos de estratégias são produzidos como resultado de determinado processo? Para elucidar essa questão, Miles e Snow (1978) partiram do pressuposto de que estruturas e processos organizacionais refletem interações previamente estabelecidas com o ambiente e que a liberdade de escolha dos gerentes associada às especificidades das estruturas, processos e tecnologias de cada organização faz com que o escopo das combinações estratégicas que podem emergir desse contexto seja extremamente vasto. Quatro tipos ideais foram utilizados para agrupar organizações que apresentavam similaridade estratégica na forma de responder ao ambiente e em relação a características internas das empresas.

Os autores utilizaram um continumm variando de alto nível de proatividade até o extremo alto nível de reatividade. No primeiro nível do continuum, encontra-se o nível ocupado pelo tipo organizacional denominado prospectivo. Organizações prospectivas são criadoras da mudança e buscam continuamente novas oportunidades no mercado, respondendo proativamente às tendências emergentes. Elevados investimentos em pesquisa e desenvolvimento de novos produtos e mercados possibilitam avanços significativos na posição da empresa, mas não necessariamente eficiência - dado o alto preço de tentar identificar hoje as demandas do mundo futuro. As tecnologias utilizadas nessas organizações geralmente requerem baixo nível de especialização e alto nível de 
interdependência e são flexíveis e não rotineiras. As estruturas apresentam tendência à alta organicidade e descentralização, baixo nível de formalização e especialização e reduzido número de níveis hierárquicos. O segundo tipo - organizações analíticas - opera num domínio híbrido, tentando simultaneamente explorar novas oportunidades e manter-se firme em bases de atuação já consolidadas. Nas áreas de estabilidade, operações ocorrem de forma rotineira e eficiente, por meio do uso de estruturas e processos formalizados. Nos domínios inexplorados, gerentes escaneiam continuamente o ambiente, buscando identificar novas ideias e produtos, que são rapidamente incorporados. Por causa do foco dual em produção de massa e pesquisa e desenvolvimento, essas organizações tendem a crescer rapidamente. Outra especificidade desse tipo ideal é sua posição intermediária entre organizações prospectivas e defensivas, e a tendência de que gerentes dessas organizações adotem estratégias que caracterizam esses tipos isoladamente (MILES; SNOW, 1978).

Caminhando para um nível crescente de reatividade na escala está um terceiro tipo composto de organizações defensivas. Elas se caracterizam por uma estreita orientação para a filosofia produto-mercado, operam em áreas limitadas e não apresentam perspectiva de expansão de domínios via identificação de novas oportunidades. Produzir com baixos custos, obter ganhos com a utilização de economias de escala e por intermédio da utilização de tecnologias de rotina são prioridades nessas organizações. Estruturas, processos e tecnologias são estáveis, raramente ajustados, e devem operar da forma mais eficiente possível. O quarto e último tipo é o mais reativo deles e engloba as organizações reativas. Embora gerentes dessas organizações demonstrem capacidade para perceber mudanças no ambiente, eles geralmente se mostram incapazes de responder efetivamente às demandas ambientais. De forma geral, são frágeis as relações entre estratégia e estrutura e ajustes para atender a demandas do ambiente são considerados apenas sob forte pressão externa. A diferença básica entre o tipo reativo e o defensivo é que gerentes de organizações reativas não apresentam nenhuma consistência quando solicitados a estabelecer estratégias gerenciais que, pelo menos teoricamente, deveriam ser capazes de responder a situações de mercado.

Organizações em momentos de crise geralmente tendem a apresentar comportamentos estratégicos defensivos ou reativos, embora teoricamente se possa arguir que são exatamente as estratégias proativas e analíticas aquelas capazes de conduzir a mudanças (MILES; CAMERON, 1982). Nos hotéis pesquisados, buscou-se investigar o tipo estratégico com o qual essas organizações mais fortemente se identificam.

\section{UMA BREVE CONTEXTUALIZAÇÃO DO SETOR HOTELEIRO NO BRASIL}

A relevância do setor hoteleiro num país com o tamanho e as perspectivas turísticas que o Brasil oferece é inequívoca. O parque hoteleiro nacional, segundo a Associação Brasileira da Indústria de Hotéis $(\mathrm{ABIH})$, conta atualmente com cerca de 25 mil meios de hospedagem, dos quais, 18 mil são hotéis e pousadas. Estima-se que a hotelaria nacional tenha um faturamento da ordem de US $\$ 2$ bilhões ao ano, detendo um patrimônio de $\mathrm{R} \$ 78,7$ bilhões, com um gasto anual em mão de obra em torno de $\mathrm{R} \$ 2$ bilhões. Além disso, gera uma arrecadação de mais de US\$ 400 milhões em impostos, taxas e contribuições, sendo que, de cada dez empregos da população economicamente ativa, um está vinculado ao setor do turismo.

À exceção das grandes cadeias de hotéis, verifica-se no setor uma significativa predominância de micro e pequenas empresas, frequentemente de propriedade familiar, sendo que, em geral, no Brasil, elas dispõem de condições limitadas para a realização de investimentos em treinamento, tecnologia, propaganda e infra-estrutura (GORINI;MENDES, 2005).

A década de 1970 trouxe oportunidades de expansão do setor no Brasil, em virtude do desenvolvimento da infra-estrutura dos transportes aéreo e rodoviário, o que possibilitou o desenvolvimento de novos empreendimentos. Também contribuíram para alavancar o setor de turismo o elevado nível de atividade econômica no período e os incentivos para novos investimentos oferecidos pela Embratur, com financiamentos do BNDES (Banco Nacional de Desenvolvimento Econômico e Social) e os incentivos fiscais (Fiset, Fungetur, Finam e Finor) (GORINI; MENDES, 2005).

A crise econômica e o quadro de estagnação do início dos anos 80 causaram desaceleração no ritmo de crescimento do setor, cujo quadro foi agravado com o fim dos financiamentos de longo 
prazo e dos incentivos fiscais (RODRIGUES, 2002). No fim dos anos 1990, devido sobretudo às novas linhas de crédito especial para a construção de hotéis e à estabilidade econômica alcançada a partir do Plano Real, o crescimento geométrico da oferta de leitos no setor hoteleiro suplantou consideravelmente o crescimento linear da demanda, causando uma acentuada queda nas taxas de ocupação. $\mathrm{O}$ ano de 2002 apresentou o pior resultado da última década, aliando a crise do setor hoteleiro às turbulências econômicas vivenciadas, na época, no Brasil e no mundo (BONFATO, 2006).

O setor hoteleiro de Belo Horizonte também enfrentou turbulências entre os anos de 2001 e 2005, em resposta à construção de um grande número de apart-hotéis e à entrada em cena das redes internacionais, com uma acentuada queda nas taxas de ocupação, dos valores das diárias e da rentabilidade. Alguns hotéis chegaram a decretar falência, e os sobreviventes resistiram com extrema dificuldade (ABIH-MG, 2009). A partir de 2005, o setor hoteleiro belo-horizontino começou a se recuperar, elevando gradativamente suas taxas de ocupação: eram de 57,35\% em 2005, 64,06\% em 2007 e, ao fim do ano de 2008, chegaram a 68,41\%. Também o valor da diária vem crescendo, tendo passado de um valor médio de $R \$ 114,29$, em 2005, para $R \$ 169$,72, em 2008. Entretanto, há muitas diferenças entre os hotéis que compõem o setor, em Belo Horizonte, como claramente mostra a pesquisa realizada.

\section{ASPECTOS METODOLÓGICOS}

A presente pesquisa, de caráter descritivo, orienta-se a partir da estratégia qualitativa de pesquisa coerente por propiciar a captação da essência subjetiva dos fenômenos atrelados a seu contexto (TRIVIÑOS, 1987). Como método de análise empírica, adotou-se o estudo de caso, que consiste na investigação empírica de um fenômeno social cujos limites com o seu contex to não são bem definidos (YIN, 2005). Esse método possibilita o necessário aprofundamento na compreensão dos significados expressos pelos sujeitos e na interação destes, conformando a construção histórico-social de suas realidades.

A análise empírica será operacionalizada a partir do modelo de Miles e Snow (1978), sendo que, na presente pesquisa, adotou-se o continuum estratégico composto pelos tipos prospectivo - analítico - defensivo, conforme resultados validados por Doty et al. (1993), Hambrick (1981, 1983), Zahra e Pearce (1990). Nessas pesquisas, os autores encontraram dificuldades para operacionalizar os quatro tipos originais descritos por Miles e Snow (1978) e optaram por fundiros tipos reativo e defensivo, opção que também adotamos nesta pesquisa. No Quadro 1 estão apresentadas algumas características de cada um dos tipos estratégicos que serão utilizados nesta pesquisa como as dimensões escolhidas para a análise dos hotéis pesquisados:

\section{Estratégia}

Prospectiva

Estratégias: produz a inovação; ênfase na busca por novos serviços e mercados; constante escaneamento ambiental.

Relação com o Mercado: busca identificar novas oportunidades de negócios e novas necessidades dos clientes; responde rapidamente a novas tendências.

Características da gestão: complexos mecanismos de coordenação e comunicação; valoriza a participação; processo decisório descentralizado; baixo nível de controle dos processos de trabalho.

Analítica Estratégias: ênfase em estabilidade; oferece os serviços tradicionais, mas enfrenta os concorrentes, oferecendo serviços sem inovatividade; mantém domínio híbrido entre os tipos prospectivo e defensivo.

Relação com o Mercado: análise custo-benefício é determinante para oferta de novos serviços, pois busca equilíbrio entre eficiência e eficácia; investimentos reduzidos.

Características da gestão: moderada centralização de controles; processo decisório moderadamente centralizado; valoriza a participação; canais hierárquicos estabelecidos. 


\begin{tabular}{|c|c|}
\hline Estratégia & Características \\
\hline Defensiva & $\begin{array}{l}\text { Estratégias: mantém a estabilidade do nicho através da alta fidelidade dos clientes tradicionais; limitada } \\
\text { gama de serviços. } \\
\text { Relações com o mercado: ênfase em eficiência, qualidade e preços, no contexto de seu nicho; tende } \\
\text { a ignorar os desafios e mudanças ambientais; baixa agressividade em termos de expansão de domínios; } \\
\text { aversão a risco. } \\
\text { Características da gestão: alto nível de formalização e controle; coordenação simples, centralização do } \\
\text { processo decisório. }\end{array}$ \\
\hline
\end{tabular}

Fonte: Adaptado de Miles e Snow (1978).

Para a definição do locus do estudo e escolha dos casos pesquisados, foram utilizados os seguintes critérios norteadores: hotéis de pequeno porte, de acordo com o conceito atribuído pelo IBGE, de estabelecimentos que têm entre 10 e 49 empregados, e localização no hipercentro de Belo Horizonte, com pelo menos três décadas de existência. Para a classificação dos hotéis foi utilizado o critério oficial da Embratur/Mtur (2002), que agrupa os hotéis em seis categorias, cujos indicadores consideram a gestão do empreendimento e a qualidade dos serviços e instalações, quais sejam: superluxo, luxo, superior, turístico, econômico e simples. Assim, a partir dos critérios anteriormente apresentados, foram selecionados três hotéis para a primeira etapa da pesquisa (que continua, com a incorporação de mais três hotéis) caracterizados no Quadro 2:

QUADRO 2 - Caracterização dos hotéis

\begin{tabular}{|c|c|c|c|c|}
\hline Hotel* & Característica & $\begin{array}{c}\text { Data de } \\
\text { fundação }\end{array}$ & $\begin{array}{c}\text { Classificação } \\
\text { Embratur }\end{array}$ & Perfil sócio-proprietário \\
\hline Alfa & $\begin{array}{l}\text { - Taxa média de ocupação: } 70 \% \\
\text { - } 65 \text { unidades habitacionais (UHs); } \\
\text { - Número de funcionários: } 10\end{array}$ & 1972 & Simples & $\begin{array}{l}\text { - Administra o hotel desde 1982; } \\
\text { - Sem formação profissional } \\
\text { específica para o setor }\end{array}$ \\
\hline Bravo & $\begin{array}{l}\text { - Taxa média de ocupação: } 80 \% \\
\text { - } 60 \text { unidades habitacionais (UHs); } \\
\text { - Número de funcionários: } 14\end{array}$ & 1972 & Econômico & $\begin{array}{l}\text { - Administra o hotel desde 1990; } \\
\text { - Sem formação profissional } \\
\text { específica para o setor }\end{array}$ \\
\hline Charlie & $\begin{array}{l}\text { - Taxa média de ocupação: } 65 \% \\
\text { - } 97 \text { unidades habitacionais (UHs); } \\
\text { - Número de funcionários: } 25\end{array}$ & 1952 & Econômico & $\begin{array}{l}\text { - Administra o hotel desde 2003; } \\
\text { - Sem formação profissional } \\
\text { específica para o setor }\end{array}$ \\
\hline
\end{tabular}

Fonte: Dados da pesquisa.

Nota: * Os nomes utilizados para designar os hotéis são fictícios. 
Resguardadas as peculiaridades de cada hotel pesquisado, o perfil dos hóspedes tradicionais se caracteriza, sobretudo, por pessoas que viajam a negócios, para participar de eventos, para a realização de tratamentos de saúde ou ainda para prestar provas de concursos. Dentre as principais ocupações dos atuais hóspedes destacam-se: turistas a passeio, representantes comerciais, vendedores, motoristas de ônibus, profissionais liberais, revendedores de feiras e, até mesmo, atletas que se hospedam durante os principais eventos esportivos da cidade.

Para coleta de dados, foi elaborado um roteiro de entrevistas semiestruturado, para orientar as entrevistas em profundidade realizadas com os sócios-proprietários dos empreendimentos. As entrevistas foram transcritas e, para tratamento dos dados, foi utilizada a técnica de análise de conteúdo (BARDIN, 1988) que visa a tornar evidentes os elementos ocultos da linguagem, além de organizar e buscar o significado original dos seus elementos manifestos (RODRIGUES; LEOPARDI, 1999).

\section{O HIPERCENTRO DE BELO HORIZONTE E AS ESTRATÉGIAS DOS HOTÉIS PESQUISADOS}

\section{O hipercentro de Belo Horizonte}

Evidenciar algumas etapas na dinâmica socioespacial da trajetória histórica do hipercentro de Belo Horizonte é importante neste trabalho, pois elas exerceram grande influência na definição das estratégias dos hotéis ali inseridos.

Nas décadas de 1960 e 1970, houve grande crescimento do hipercentro de Belo Horizonte, com a construção de edifícios e a concentração de praticamente todas as atividades comerciais e econômicas. $\mathrm{O}$ aumento no fluxo de pessoas e veículos traz naturalmente certo caos à região central, com aumento nos índices de violência, grande concentração de ambulantes nas ruas e congestionamentos, dentre outros problemas. Começa assim o movimento de migração das camadas de mais alta renda para outros locais, como a região da Savassi, inicialmente associada a um comércio mais refinado e elegante. O hipercentro vai então sendo abandonado pela população de poder aquisitivo mais elevado, primeiramente como local de moradia e, posteriormente, como local de compras e lazer. O processo de segregação social no espaço traz consigo a associação do hipercentro a um lugar perigoso e empobrecido, fomentando o ciclo vicioso imposto pelo próprio processo (VILELA, 2006).

Os anos 1980 trazem dois fatores que vão intensificar ainda mais a decadência do hipercentro da cidade, especialmente como lugar de compras e lazer: a difusão do uso do automóvel como meio de transporte e o surgimento dos shopping centers. A década de 1990 assiste a inúmeras mudanças na estrutura populacional e econômica do espaço urbano da metrópole, dentre as quais se pode destacar a intensificação do crescimento das favelas, o aumento significativo dos registros de criminalidade e a deterioração urbana do hipercentro de Belo Horizonte.

Diante da realidade de deterioração física, econômica e social do hipercentro, o poder público implantou, em 2004, o Programa Centro Vivo, com o objetivo de recuperar o espaço urbano do hipercentro da cidade. Eram enormes os desafios de revitalização e recuperação do hipercentro de Belo Horizonte. Numa tentativa de contrabalançar as políticas de requalificação com ações sociais, o Programa Centro Vivo apresentou uma proposta de organização articulada entre os atores públicos e privados, no sentido de promover estratégias de desenvolvimento por meio de ações conjuntas. Dentre as principais medidas desenvolvidas pelo projeto, foram propostas a retirada dos camelôs e ambulantes das ruas e seu remanejamento para shoppings populares; a revitalização de praças, ruas e avenidas, paralelamente ao tombamento de conjuntos arquitetônicos e a criação da Guarda Patrimonial Municipal, dentre outras ações (PMBH, 2008).

Adicionalmente, foi implantado o projeto Olho Vivo, por meio de uma parceria entre a Câmara de Dirigentes Lojistas de Belo Horizonte (CDL) e os governos municipal e estadual, o que viabilizou a instalação de 72 câmeras de vigilância nas regiões tradicionais de comércio. Após a instalação, pesquisas mostraram que os índices de violência revelaram uma redução de $40 \%$, comparativamente, entre os anos de 2004 e 2005.

Políticas urbanas de revitalização de áreas centrais são usualmente polêmicas e muitas vezes produzem resultados mais estéticos, de curto prazo e, não raro, com objetivos políticos questionáveis. Não se vai aqui empreender a discussão da eficácia das políticas ainda em implantação no hipercentro de Belo Horizonte, mas levá-las em consideração quando 
da avaliação das estratégias adotadas pelos hotéis pesquisados. Estariam essas políticas produzindo efeitos sobre os hotéis localizados no hipercentro, interferindo na (re)definição de suas estratégias?

\section{Análise dos hotéis pesquisados no hipercentro de Belo Horizonte}

As estratégias apresentadas pelos hotéis pesquisados, na sua maioria emergentes e defensivas, serão apresentadas por meio de três eixos temáticos, quais sejam: estratégias, relações com o mercado e características da gestão.

\section{Estratégias}

A aquisição do Hotel Alfa pelos atuais proprietários, em 1982, foi consequência de uma estratégia de escoamento do excesso de demanda do outro hotel que possuíam, por conta de um convênio existente entre o hotel e uma grande empresa da construção civil, que na época hospedava seus funcionários antes de enviá-los para trabalhar no exterior. Como o outro hotel, que os atuais proprietários do Hotel Alfa já possuíam no hipercentro, não conseguia mais atender a toda a demanda da empresa, foi necessário adquirir o Hotel Alfa, localizado próximo à rodoviária. A predominância de hóspedes oriundos do convênio com essa empresa, durante quase uma década, trouxe estabilidade e uma elevada taxa de ocupação para o hotel.

Muitas vezes, a aquisição ou fundação de um novo negócio está atrelada a uma postura mais prospectiva, quando os sócios assumem riscos, investem na inovação, oferecendo novos serviços, a partir de um contínuo processo de monitoramento do mercado. Porém, no caso do Hotel Alfa, a aquisição do hotel ocorreu em decorrência de uma demanda já existente, caracterizando-se, dessa forma, por uma postura predominantemente defensiva por parte dos empreendedores, que buscavam manter a clientela já conquistada, sem a oferta de novos serviços e sem o compromisso com qualquer processo de inovação organizacional.

Outro ponto que merece destaque e que reforça a postura defensiva do Hotel Alfa seria a manutenção dos hóspedes tradicionais, anteriores à aquisição do hotel pelos atuais sócios, sendo que o hotel foi fundado em 1972 e adquirido pelos atuais proprietários apenas em 1982. Por estar localizado muito próximo a uma tradicional zona boêmia de Belo Horizonte, o Hotel Alfa, mesmo antes de ser adquirido pelos atuais proprietários, já servia como residência para muitas prostitutas que trabalhavam em seu entorno. Ainda hoje, cerca de 20 quartos (aproximadamente $30 \%$ de sua capacidade) são ocupados por mulheres que moram no hotel e trabalham nos estabelecimentos boêmios do entorno.

Caminhando para uma perspectiva estratégica mais analítica, o Hotel Bravo investe em ações de complementaridade, utilizadas pelos proprietários para reduzir a sazonalidade que atinge o setor hoteleiro de forma geral. Embora seja uma organização de pequeno porte (60 leitos), o hotel busca captar, além de hóspedes que viajam a negócios, também turistas que visitam a cidade em época de férias, sendo que, dessa forma, conseguiu atingir uma elevada taxa de ocupação (em torno de $80 \%$ ). Aliado a isso, o hotel investiu em diversas reformas na sua infraestrutura, desde os anos 1990. As melhorias que foram incorporadas trouxeram também a necessidade de reajuste nas tarifas, o que, por sua vez, influenciou na alteração do perfil dos hóspedes, o que já era um objetivo previamente delineado pela direção do hotel. $\mathrm{O}$ hóspede hoje é convidado a visitar as dependências do hotel antes de se decidir pela estada, como uma forma de fazê-lo perceber a estratégia custobenefício do empreendimento. As estratégias aqui podem ser associadas à diferenciação, quando o hotel busca, no contexto de um perfil de clientela de poder aquisitivo mediano, oferecer uma boa relação custo-benefício.

Além disso, o Hotel Bravo revela importante flexibilidade em sua política de preços, usualmente empregada de forma reativa ao nível de demanda vivenciada. Embora mantenha tarifas ligeiramente superiores à média dos hotéis de sua categoria no hipercentro, promoções e descontos são praticados, sobretudo, em momentos de baixa demanda, quando o hotel flexibiliza suas tarifas, concedendo descontos maiores, além de permitir check-ins antecipados e, até mesmo, oferecendo o café da manhã extra como cortesia. Tal flexibilidade indica claramente uma postura analítica, em que ocorre uma reação frente à realidade do mercado, porém marcada, visivelmente, pela ausência de inovação, ofertando os serviços tradicionais e 
buscando a manutenção da estabilidade a partir de um equilíbrio entre eficiência e eficácia.

Por sua vez, as estratégias do Hotel Charlie são essencialmente caracterizadas pelo seu caráter defensivo. O hotel foi, dentre os analisados, o mais afetado pela decadência do hipercentro de Belo Horizonte, que o levou gradativamente à obsolescência, deixando para trás um passado de elegância e opulência, ainda hoje refletida nos detalhes arquitetônicos do prédio, nos móveis e no estilo da decoração. Dessa forma, diante das mudanças ocorridas no hipercentro, o hotel se mostrou incapaz de responder efetivamente à nova realidade descortinada, assumindo uma postura de reatividade diante da impossibilidade de manter o mesmo perfil de clientes, reagindo, sobretudo, a partir da redução do valor das diárias e buscando atender um público de menor poder aquisitivo.

Porém, paralelamente à adequação das tarifas do hotel ao novo perfil dos hóspedes, o Hotel Charlie iniciou diversas reformas, na tentativa de, gradativamente, reconquistar seu antigo público. Nesse sentido, optou, em 2004, pelo tombamento da fachada do hotel como patrimônio histórico e cultural da cidade. Atualmente, os sócios-proprietários estão buscando, com a prefeitura e outros órgãos de apoio, auxílio para a restauração dos móveis antigos que o hotel ainda conserva. $\mathrm{Na}$ visão dos gestores, o foco na reforma e ampliação do hotel dificultou de forma considerável a modernização e diversificação dos serviços oferecidos, aliando um quadro de elevados gastos com as reformas à baixa demanda. Nesse sentido, apesar de se aproximar de uma perspectiva estratégica mais analítica, o hotel ainda se mantém distante de uma postura prospectiva, uma vez que seu investimento em reformas é orientado no sentido de reconquistar seu antigo perfil de hóspedes e nível de demanda, e não no sentido de explorar novos nichos, oferecendo serviços inovadores, buscando ampliar e diversificar seu mercado.

\section{Relações com o mercado}

No contexto atual, a relação com o mercado, principalmente no tocante à concorrência, é marcada por uma postura eminentemente defensiva nos três hotéis estudados. Tais relações se caracterizam pela manutenção das operações de cada hotel em áreas limitadas, sem qualquer perspectiva ou diretriz de expansão de mercado, através da identificação de novas oportunidades. Além disso, inexistem estratégias gerenciais capazes de responder a situações de mercado, denotando uma frágil relação entre a estratégia e estrutura desses hotéis.

Como exemplo de tal visão, a gerência do Hotel Bravo afirma que, apesar de seus principais concorrentes se localizarem em seu entorno, a disputa não é acirrada, pois cada hotel já conquistou o seu público específico. As grandes redes hoteleiras nem são consideradas como concorrentes, devido à diferença de tarifa e de público-alvo. No caso do Hotel Alfa, o proprietário sequer considera a existência da concorrência. $\mathrm{Na}$ sua visão, não existem concorrentes, devido às características peculiares dos hotéis do hipercentro, à tradição de seu hotel no atendimento aos seus públicos específicos e, ainda, à elevada fidelização da demanda. Os diversos hotéis existentes em seu entorno são identificados como parceiros que, numa política de boa vizinhança, indicam hóspedes para seu hotel quando não têm disponibilidade para atendê-los. Tal prática é confirmada pelo gestor do Hotel Bravo, que também indica e recebe indicações dos hotéis vizinhos localizados em seu entorno.

Dessa forma, fica clara a postura defensiva adotada pelos hotéis em questão, que além de praticamente ignorarem os desafios e mudanças ambientais, direcionam seu foco apenas para o atendimento do nicho em que já se consolidaram e fidelizaram sua clientela tradicional, apresentando um nível de agressividade muito baixo, no quesito de expansão de mercado, indicando uma nítida aversão ao risco.

Éválido observar as diferenças evidenciadas durante a crise de demanda sofrida pelo setor hoteleiro, entre os anos de 2001 e 2004. Nesse cenário de crise, foram descritas pelos entrevistados práticas bem mais agressivas perpetradas justamente por hotéis que, no atual contexto, nem são considerados concorrentes.

Nesse sentido, os gestores dos hotéis Charlie e Bravo relataram que houve um acirramento da concorrência entre os hotéis do hipercentro e outros considerados tradicionais em Belo Horizonte. Apesar de tais hotéis atenderem habitualmente a um público mais elitizado, na conjuntura da crise baixaram drasticamente suas tarifas e passaram a disputar de forma predatória o mesmo público que os hotéis de categoria econômica. Ainda é válido 
ressaltar a passividade desses hotéis frente às ações de seus concorrentes, postura típica de organizações defensivas, nas quais, conforme já explicitado, não existem estratégias formuladas para responder a mudanças ambientais, implicando em um quadro de inércia organizacional.

\section{Características da gestão}

Finalmente, em relação às características da gestão dos hotéis analisados, mais uma vez, a postura defensiva foi fortemente evidenciada. Inicialmente é possível destacar que nenhum dos três hotéis investe ou pretende investir na profissionalização de sua gestão, e para isso são apresentadas justificativas pouco plausíveis, como, por exemplo, o receio de burocratizar excessivamente a gestão e a falta de criatividade que supostamente domina as empresas mais profissionalizadas. Outro ponto que merece atenção e que está intimamente ligado ao caráter defensivo das organizações em questão é a forte centralização do processo decisório identificada nos três hotéis estudados, em que as decisões são centralizadas na figura do proprietário. Além disso, as práticas gerenciais são focadas essencialmente na busca pela eficiência em detrimento da eficácia, restringindo a procura por novas oportunidades de negócio. Assim, organizações do tipo defensivo são pouco engajadas em desenvolvimento de novos produtos e mercados, competindo à base de preço e buscando eficiência em todos os níveis. Nesse contexto, os hotéis buscam minimizar custos, utilizam quase exclusivamente tecnologias de rotina e realizam apenas investimentos imprescindíveis.

A falta de profissionalização e a elevada centralização das decisões podem ser, ao menos em parte, influenciadas pelo caráter familiar dos hotéis estudados. Dessa forma, conforme aponta Gonçalves (2000), principalmente durante a administração do fundador, a relação com os membros da organização é condicionada por uma orientação de natureza pessoal, baseada em fidelidade e mútua confiança, norteada e disciplinada pelo patrão e dono, em detrimento de uma relação profissional e jurídica entre a empresa e os empregados. Além disso, as práticas gerenciais são caracterizadas por métodos intuitivos em detrimento de métodos mais profissionais e racionais.
A sucessão, ou, na realidade, a falta de planejamento da sucessão, surge como outro fator importante identificado nos hotéis pesquisados. Apesar de representar um dos momentos mais críticos vivenciados pela empresa familiar, marcado pela transferência do poder e do capital entre as diferentes gerações da família empresária (LEONE, 2005), não existe, em nenhum dos hotéis, qualquer preocupação no sentido de planejar o processo sucessório, que mais cedo ou mais tarde se fará necessário. Assim, a inexistência de uma cultura de planejamento para o processo sucessório parece estar atrelada à postura defensiva de tais empresas, que tendem a reagir somente sob forte pressão do ambiente, sendo que, nesse caso, é possível supor que a sucessão ocorrerá de forma desordenada e imediatista, sendo encarada como prioridade apenas no momento em que se apresentar como inevitável e urgente. Tal observação deve ser apontada como um fator crítico evidenciado pelo presente estudo, uma vez que a falta de planejamento dos processos sucessórios pode conduzir tais empreendimentos à falência. Há que se destacar ainda que parece constituir uma prática usual, pelo menos nos hotéis pesquisados, a venda do empreendimento, ao invés da passagem intergeracional. Talvez o fato de que todos os atuais proprietários adquiriram o negócio de um outro dono (alguns, dos fundadores) explique a projeção dessa mesma situação para o futuro do negócio.

No caso do Hotel Alfa, a falta de planejamento da sucessão ainda se alia ao conflito de gerações. $\mathrm{O}$ atual proprietário narrou um interessante episódio sobre a tentativa de inserção de seu filho no negócio: logo que se formou em Administração, o filho foi chamado para trabalhar com o pai, sendo que, em pouco tempo, declarou sua intenção de transformar o hotel em uma casa de prostituição, como outras que cercam o empreendimento, o que, em sua perspectiva, seria muito mais rentável. O pai, e atual proprietário, se negou a considerar a proposta, alegando questões morais, e o conflito foi tão intenso que ambos decidiram que o filho se afastaria da gestão do hotel, buscando construir sua carreira no mercado.

Essa narrativa, embora cotidiana no universo das pequenas empresas familiares, evidencia o problema do conflito de gerações, as diferentes visões de negócio e as dificuldades de sobrevivência que a organização provavelmente terá que enfrentar no 
futuro. Sob o aspecto estratégico, revela uma empresa vulnerável em relação ao processo de formação da estratégia, altamente dependente da visão do gestor em relação ao futuro da organização.
A partir das análises norteadas pelos três eixos temáticos descritos, foi possível agrupar, no Quadro 3, as diferentes estratégias elencadas pelos pequenos hotéis do hipercentro.

QUADRO 3 - Estratégia, relações com o mercado e características da gestão nos hotéis pesquisados

\begin{tabular}{|c|c|c|}
\hline Eixo temático & Tipologia defensiva & Tipologia analítica \\
\hline Estratégias & $\begin{array}{l}\text { - Manutenção dos hóspedes tradicionais, } \\
\text { anteriores à aquisição do hotel; } \\
\text { - Mudança do perfil dos hóspedes, pressionada } \\
\text { pelo quadro de decadência do hotel; } \\
\text { - Aquisição do Hotel Alfa como estratégia } \\
\text { de escoamento do excesso de demanda do } \\
\text { outro hotel. }\end{array}$ & $\begin{array}{l}\text { - Busca pela diferenciação do perfil dos hóspedes; } \\
\text { - Busca de alternativas para a questão da } \\
\text { sazonalidade; } \\
\text { - Flexibilização das tarifas e condições do hotel } \\
\text { em face a um quadro de baixa demanda; } \\
\text { - Investimento na infra-estrutura do hotel como } \\
\text { forma de reconquistar o público tradicional. }\end{array}$ \\
\hline $\begin{array}{l}\text { Relações com } \\
\text { o mercado }\end{array}$ & $\begin{array}{l}\text { - Percepção de hotéis no entorno como } \\
\text { parceiros e não como concorrentes; } \\
\text { - Acomodação em um nicho específico de } \\
\text { mercado, sem perspectiva ou diretriz de } \\
\text { expansão; } \\
\text { - Passividade dos hotéis frente às ações } \\
\text { competitivas de seus concorrentes, em } \\
\text { momentos de crise, denotando a escassez de } \\
\text { estratégias gerenciais capazes de responder a } \\
\text { situações de mercado. }\end{array}$ & \\
\hline $\begin{array}{l}\text { Características } \\
\text { da gestão }\end{array}$ & $\begin{array}{l}\text { - Forte centralização do processo decisório na } \\
\text { figura do proprietário; } \\
\text { - Opção pela não profissionalização da gestão; } \\
\text { - Inexistência de uma cultura de planejamento } \\
\text { para o processo sucessório; } \\
\text { - Práticas gerenciais focadas na busca pela } \\
\text { eficiência em detrimento da eficácia, restringindo } \\
\text { a busca por novas oportunidades de negócio. }\end{array}$ & \\
\hline
\end{tabular}

Fonte: Dados da pesquisa.

\section{CONSIDERAÇÕES FINAIS}

Por meio desta pesquisa foi possível traçar um quadro inicial acerca do processo e do perfil estratégico de hotéis de pequeno porte localizados na região central de um grande hipercentro urbano e que vêm enfrentando grandes mudanças em seu segmento de atuação. Embora as conclusões aqui sejam limitadas pelo escopo do trabalho, acredita-se que, caso se amplie o número de estabelecimentos pesquisados, não se delineará uma realidade radicalmente diferente dessa. Novas pesquisas em outros centros urbanos, porém, seriam relevantes para complementar os resultados aqui obtidos.

A tipologia utilizada por Miles e Snow (1978) para configurar as organizações defensivas (trabalhada no presente estudo, conjugada com a tipologia reativa) descreve de forma bastante precisa 
o contexto dos hotéis pesquisados, apesar de alguns elementos analisados se aproximarem da tipologia analítica. Conclui-se, assim, que os empreendimentos estudados são orientados para o mercado, operam em áreas limitadas, não apresentam perspectivas de crescimento, são norteados pelas estratégias de custo e utilizam tecnologias rotineiras. Suas estruturas organizacionais e processos de trabalho são simples, estáveis e buscam eficiência, em primeiro lugar. Não se observam também significativas interações entre a estrutura e a estratégia adotada, até porque as estruturas são raramente ajustadas e as estratégias vão sendo implementadas à medida que determinada ameaça real é colocada para essas empresas. Como afirmam os gestores entrevistados, suas estratégias emergem em virtude do momento e da ameaça enfrentada, que deve ser forte o suficiente para gerar uma reação. Mesmo ameaças reais, como a concorrência estabelecida pelos estabelecimentos existentes no entorno, são ignoradas, negligenciadas ou mesmo negadas pelos gestores desses hotéis. Igualmente, situações plausíveis em relação a um futuro próximo não são vistas como ameaças, nem se estabelecem alternativas de ação caso elas venham a se concretizar, como evidenciado no caso dos processos sucessórios.

As estratégias emergentes constituem o tipo mais frequente e surgem de forma quase errática para enfrentar questões relevantes, mas pontuais, como uma queda na demanda por razões de sazonalidade ou uma política de preços mais agressiva por parte de um concorrente. As estratégias deliberadas, por sua vez, são representadas por padrões mais consistentes de ações, tendem a se firmar ao longo do tempo e constituem uma constante na fala de cada uma das gerências em relação a aspectos tais como o perfil almejado da clientela, as estratégias adotadas em relação ao tipo de serviço ofertado, a política de preços do estabelecimento, as alternativas (ou mesmo a inexistência delas) para enfrentamento da concorrência e os planos em relação à infraestrutura do hotel dentre outras. Estratégias emergentes e deliberadas, na maioria das pequenas empresas, se complementam e oferecem ao processo estratégico a flexibilidade e o dinamismo que ele precisa ter.

Porém, não é prudente afirmar que os processos estratégicos desenvolvidos pelas organizações pesquisadas são inadequados. Um dos hotéis existe há quase 60 anos, os outros dois há quase 40 .
Assim, situações de profundas mudanças foram experimentadas por esses hotéis, que sobreviveram a grandes desafios sobre os quais essas pequenas organizações tinham pouco poder de interferência, como as transformações urbanas, a deterioração do hipercentro da cidade e a entrada em cena de grandes redes hoteleiras. O que explica a sobrevivência deles durante esse período provavelmente foi o fato de terem claramente definido o nicho de mercado pelo qual competiam, o perfil da clientela a ser trabalhado e as políticas de preço condizentes com esse perfil. Novas perspectivas, contudo, se abrem hoje para esses hotéis, mas, para planejar o futuro, as estratégias de sobrevivência adotadas no passado provavelmente não serão adequadas. Serão essas organizações capazes de migrar para um processo estratégico mais condizente com essas novas perspectivas? Somente por meio do acompanhamento longitudinal desse processo será possível responder a essa questão.

\section{REFERÊNCIAS}

ASSOCIAÇÃO BRASILEIRA DA INDÚSTRIA HOTELEIRA - ABIH. O parque hoteleiro nacional. Disponível em: <http://www.abih.com.br/site.php>. Acesso em: 14 fev. 2009.

BARDIN, L. Análise de conteúdo. Lisboa: Edições 70, 1988.

BOnfatO, A. C. Desenvolvimento de hotéis. 2. ed. São Paulo: SENAC, 2006.

DOTY, D. H. et al. Equifinality and organizational effectiveness: a test of two configurational theories. Academy of Management Journal, v. 36, n. 6, p. 1196-1250, 1993.

GONÇALVES, J. S. R. C. As empresas familiares no Brasil. RAE Light, v. 7, n. 1, p. 7-12, 2000.

GORINI, A. P. F.; MENDES, E. F. Setor de turismo no Brasil: segmento de hotelaria. BNDES Setorial, n. 22, p. 111-150, 2005.

HAMBRICK, D. C. Environment, strategy, and power within top management teams. Administrative Science Quarterly, v. 26, p. 253-276, 1981.

Some tests of the effectiveness and functional atributes of Miles and Snow's strategic types. Academy of Management Journal, v. 26, n. 1, p. 5-26, 1983. 
INSTITUTO BRASILEIRO DE TURISMO EMBRATUR. Deliberação Normativa n. 429 de 23 de abril de 2002. Regulamento do sistema de classificação de meios de hospedagem. Brasília: EMBRATUR/ MTUR, 2002. Disponível em: <http://200.143.12.85/ turismo/opencms/institucional/legislacao/arquivos/ deliberacao_normativa_n_429_23_abril_2002.html>. Acesso em: 10 fev. 2009.

LEONE, N. M. C. P. G. Sucessão na empresa familiar: preparando as mudanças para garantir a sobrevivência no mercado globalizado. 2. ed. São Paulo: Atlas, 2005.

MILES, R. E.; CAMERON, K. S. Coffin nails and corporate strategies. Englewood Cliffs, NJ: Prentice Hall, 1982.

MILES, R. E.; SNOW, C. C. Organizational strategy, structure and process. New York: McGraw Hill, 1978.

MINTZBERG, H. Patterns in strategy formation. International Studies of Management and Organization, v. 9, n. 3, p. 67-86, 1979.

MINTZBERG, H.; AHLSTRAND, B.;LAMPEL,J. Safári de estratégias: um roteiro pela selva do planejamento estratégico. Porto Alegre: Bookman, 2000.

MINTZBERG, H.; QUINN, J. B. (Org.). O processo da estratégia. Porto Alegre: Bookman, 2001.

NICOLAU, I. O conceito de estratégia. Lisboa: INDEG/ISCTE, 2001.

PREFEITURA DE BELO HORIZONTE - PMBH. Programas e projetos: Centro Vivo. 2008. Disponível em: <http://portalpbh.pbh.gov.br/pbh/ecp/comunidade.do? evento $=$ portlet\&pIdPlc $=$ ecp Taxonomia MenuPortal\&app $=$ programaseprojetos $\& \operatorname{tax}=1206$ $6 \&$ lang $=$ pt_BR\&pg $=6080 \& \operatorname{taxp}=0 \&>$. Acesso em: 14 fev. 2009.

RODRIGUES, R. M. Histórico de desenvolvimento de hotéis no Brasil. Hotel Investment Advisors (HIA). 2002. Disponível em: <http://www.hia.com.br/ artigo_historico_do_desenvolvimento.htm $>$. Acesso em: 14 fev. 2009.

RODRIGUES, M. S. P.; LEOPARDI, M. T. O método de análise de conteúdo: uma versão para enfermeiros. Fortaleza: Fundação Cearense de Pesquisa e Cultura, 1999.

TRIVIÑOS, A. R. S. Introdução à pesquisa em ciências sociais: pesquisa qualitativa em educação. São Paulo: Atlas, 1987.
VILELA, N. M. Hipercentro de Belo Horizonte: movimentos e transformações espaciais recentes. Minas Gerais. 2006. 230 f. Dissertação (Mestrado em Administração) - Universidade Federal de Minas Gerais, Belo Horizonte, 2006.

WILSON, D, C.; JARZABKOWSKI, P. Pensando e agindo estrategicamente: novos desafios para a análise estratégica. Revista de Administração de Empresas, v. 44, n. 4, p. 11-20, 2004.

YIN, R. K. Estudo de caso: planejamento e métodos. Porto Alegre: Bookman, 2005.

ZAHRA, S. A.; PEARCE II, J. A. Research evidence on the Miles-Snow typology. Journal of Management, v. 16, n. 4, p. 751-768, 1990.
Recebido: 14/06/2009

Received: 06/14/2009

Aprovado: 10/08/2009

Approved: 08/10/2009

REBRAE. Revista Brasileira de Estratégia, Curitiba, v. 1, n. 2, p. 213-225, maio/ago. 2008 